\title{
Using an Acceptance and Commitment Therapy app to Reduce Anxiety for Students and Employees
}

\author{
Rebecca J. Sargisson ${ }^{1, *}$, Fengshan Li $^{1}$, Deborah Lobo ${ }^{1}$ and Maree Roche ${ }^{2}$ \\ ${ }^{1}$ School of Psychology, University of Waikato, New Zealand \\ ${ }^{2}$ School of Human Resources and Leadership, University of Waikato, New Zealand
}

\begin{abstract}
Smartphone applications may ensure greater access to services for the many people who experience anxiety and other psychological issues but do not receive adequate treatment. ACTCompanion is a mHealth application that incorporates Acceptance and Commitment Therapy principles into daily exercises that assist the user to confront their negative internal experiences and work towards valued outcomes. We used a single-subject A-B design with nine students and 10 employees experiencing high daily anxiety. Participants completed a battery of questionnaires before and after app use. They completed the DAS-A regularly so we could monitor anxiety levels over time. Daily anxiety levels reduced in the intervention phase, and remained low for six participants for whom follow-up data were available. There was also a significant improvement in scores of anxiety, depression, stress, positive and negative effect, psychological flexibility, and mindfulness. Our results suggest that mHealth applications have potential to improve people's psychological functioning.
\end{abstract}

\author{
Publication History: \\ Received: November 01, 2019 \\ Accepted: December 24, 2019 \\ Published: December 26, 2019

\section{Keywords:} \\ Acceptance and Commitment \\ Therapy, Anxiety, Depression, \\ Employees, Smartphone \\ Application, Students
}

\section{Introduction}

The increase in the experience of depression, stress, and anxiety, is reflected in many segments of the population [1]. Anxiety and stress impair quality of life among working-age populations, and impede academic achievement for university students. The percentage of students experiencing anxiety- or depression-related disorders is estimated to range from $13 \%$ to $21 \%[2,3]$, while, in some samples, $31 \%$ of employees report that most work days involve stress [4]. Estimates of student anxiety and depression are high in New Zealand, with $20 \%$ of university students experiencing anxiety and 39\% reporting disturbed sleep patterns due to anxiety and depression [5]. The cost to employers of mental illness is estimated to be extremely high, third only to hypertension and heart disease, according to data from a large American sample [6].

University students diagnosed with depression and anxiety achieve poorer academic outcomes compared with other students $[7,8]$. For employees, prolonged high-intensity stress can ultimately lead to burnout [9], which interferes with a person's performance at work [10]. Anxiety also predicts depressive symptoms [11]; individuals who suffer from long-term anxiety may develop depression [12].

People suffering from anxiety may attempt to avoid, or escape from, anxiety-provoking thoughts and situations, which may serve to maintain the anxiety [13]. Prolonged anxiety may make it difficult for people to recover from negative emotions, resulting in the inability to regulate their moods, which exacerbates anxiety [14].

While Cognitive Behavioral Theory (CBT) has been a common treatment for a variety of psychological disorders, there is increasing interest in mindfulness-based alternatives [15]. Acceptance and Commitment Therapy (ACT) is one attempt to incorporate the concept of mindfulness into treatment [16]. Similar to CBT, the preliminary focus of ACT is to educate people to recognise negative internal events [17]. However, where CBT focuses on diminishing negative internal events, ACT promotes opening up to those negative thoughts. For instance, anxiety is negatively viewed, and, as a result, people may attempt to replace anxiety-provoking thoughts with other behaviours to create distraction, to suppress the disturbing thoughts, or to avoid situations that lead to unwanted experiences [18]. However, thought suppression is generally ineffective [18] and can actually increase the frequency and saliency of thoughts [10]. ACT, then, promotes psychological flexibility through reducing experiential avoidance; the avoidance of experiences, such as anxiety, associated with undesired personal events [18]. Fletcher and Hayes [20] describe psychological flexibility as the ability to be fully present and aware of the internal thoughts and feelings, including those that are negative, the ability to accept the experiences and avoid escaping from them, but to commit to actions that are consistent with one's values.

Case studies, multiple-baseline treatment studies, single randomized clinical trials, and meta-analyses have provided evidence for the efficacy of ACT for a variety of problems, including anxiety and depression [21-24], stress [25-29], insomnia [30], substance abuse [31], social anxiety [32], panic disorder [22], and posttraumatic stress disorder [33].

Given that university students and employees likely face a range of issues, a transdiagnostic intervention suitable for a broad array of mental disorders would be very useful [34]. ACT could be an appropriate tool because the approach is not limited by diagnostic presentations, severity and duration of the disturbance, or demographic difference [35].

Universities often offer student health services including counselling support. However, those counselling sessions are limited as they are often understaffed or staffed by less qualified therapists [36], and students may not have time to avail themselves of these services if their study schedule is tight [3]. Moreover, many students do not seek

"Corresponding Author: Dr. Rebecca Joanne Sargisson, School of Psychology University of Waikato, Durham St, Tauranga 3112, New Zealand, Tel: +64 7 8379580; E-mail: rebecca.sargisson@waikato.ac.nz

Citation: Sargisson RJ, Li F, Lobo D, Roche M (2019) Using an Acceptance and Commitment Therapy app to Reduce Anxiety for Students and Employees. Int J Psychol Behav Anal 5: 164. doi: https://doi.org/10.15344/2455-3867/2019/164

Copyright: (C) 2019 Sargisson et al. This is an open-access article distributed under the terms of the Creative Commons Attribution License, which permits unrestricted use, distribution, and reproduction in any medium, provided the original author and source are credited. 
Citation: Sargisson RJ, Li F, Lobo D, Roche M (2019) Using an Acceptance and Commitment Therapy app to Reduce Anxiety for Students and Employees. Int J Psychol Behav Anal 5: 164. doi: https://doi.org/10.15344/2455-3867/2019/164

Page 2 of 6

psychological services for various reasons [2,37-40]. Similarly, an estimated two-third of Australian adults who meet the criteria for a mental disorder do not consult a mental health professional [41].

The development of smartphone applications (apps) for mental wellbeing has escalated in recent years [42]. Smartphone healthcare apps present a global, cost-effective, and convenient approach to increasing demands for mental healthcare [43]. Apps can provide programmes which positively affect those with mental health conditions, such as stress reduction [44], depression [44], and anxiety reduction [45].

Despite the rapid pace in smartphone app development and growing empirical support for their utility, few studies have specifically explored the implementation of self-help apps based on ACT within populations experiencing stress and anxiety. In the current research, we provided the ACT Companion ${ }^{\mathrm{TM}}$ app to participants from two distinct populations; undergraduate university students and employees in various industries to examine whether the app was helpful in reducing anxiety. We used a single-subject approach where we monitored daily anxiety levels before, during, and after app use. Additionally, we administered a battery of questionnaires to assess aspects of anxiety, depression, and psychological flexibility before and after app use. We hypothesised, firstly, that scores of anxiety, stress, depression, and negative affect would decrease as a result of app use. Secondly, we predicted that participants' mindfulness, psychological flexibility, and acceptance and wellbeing would increase following app use.

\section{Method}

\section{Participants}

To be eligible for inclusion in the study, participants had to have a mobile device (smartphone or android), not be undergoing psychological treatments or taking psychoactive medications, and score at or above 50 on the Daily Assessment of Symptoms-Anxiety (DAS-A). The cut-off score was set at 50 in order to enable detection of reductions in anxiety over time.

Students: One male and eight female students of psychology at the University of Waikato, labelled S1 - S9, aged between 19 and 33 years, met the inclusion criteria and completed the study.

Employees: Four male and six female people, labelled E1 - E10, aged between 25 and 60 years met the inclusion criteria and completed the study. Three were teachers or vocational or occupational consultants, two were solicitors, two were support workers, one a sales manager, one a resource planner, and one worked in information technology.

\section{Materials}

Participants were given free access to the full version of the ACTCompanion $^{\circledR}$ app on their own mobile device.

\section{Measures}

Table 1 lists the measures we used in the study. We asked participants to complete the DAS-A throughout the study to monitor the daily change in anxiety level. We used the State-Trait Anxiety Inventory for Adults (STAI), Hospital Anxiety and Depression Scale (HADS), Perceived Stress Scale-10 (PSS-10), and The Positive and Negative Affect Scales (PANAS) to measure participants' anxiety, stress, and depression, and the Mindful Attention Awareness Scale (MAAS), and the Acceptance and Action Questionnaire (AAQ-II) to measure psychological flexibility and acceptance at pre- and post-intervention.

\begin{tabular}{|l|l|l|}
\hline Measure & What it measures & Frequency \\
\hline DAS-A & Anxiety level in the past 24hr & Daily \\
\hline STAI -Y 1 & Current state of anxiety & Pre and post \\
\hline STAI -Y 2 & Disposition to react anxiously & Pre and post \\
\hline HADS- A & Anxiety symptoms & Pre and post \\
\hline HADS- D & Depression symptoms & Pre and post \\
\hline PSS & Perceived stress & Pre and post \\
\hline PANAS & Positive and negative affect & Pre and post \\
\hline MAAS & $\begin{array}{l}\text { Mindfulness, attention and } \\
\text { awareness }\end{array}$ & Pre and post \\
\hline AAQ-II & Psychological flexibility & Pre and post \\
\hline
\end{tabular}

Table 1: Measures used in the study.

\section{Design}

We used a single-subject A-B design with two main phases; baseline (A) and intervention (B). For six participants, we obtained 2 - 3 days' of DAS-A scores a minimum of 6 months after they finished using the app; Follow-up (C).

\section{Procedure}

Ethical approval for the research was given by the School of Psychology Research and Ethics Committee under delegated authority of the Human Research Ethics Committee of the University of Waikato. Potential participants contacted us in response to advertisements placed at the University of Waikato, large workplaces in the region, and on social and news media. Once they made contact, we supplied them with an information sheet and, if they were still interested in participating, we met with them either in person or via skype to explain the study and obtain informed consent. Participants who consented first completed the battery of questionnaires on Qualtrics ${ }^{\oplus}$. We asked them to complete the DAS-A every day for a minimum of 3 days.

During the intervention phase, we gave participants access to the app and asked them to use the app as much as they wanted to, but to complete at least one activity per day. We asked them to continue to complete the DAS-A each day. While we received scores less often than daily for some participants, all participants completed the daily questionnaires regularly.

As a follow-up, we received 1 - 3 days' worth of completed DAS-A questionnaires from three of the nine students, S2, S5, and S9, 8, 9, and 9 months after they had completed the study, and three of the 10 employees, E6, E7, and E10, 6, 9, and 9 months after they had completed their app use.

\section{Data analysis}

We analysed the data initially using single-subject graphical analysis by plotting DAS-A scores across phases. We fitted straight lines to the data from Baseline (A) and Intervention (B) phases separately using the linear regression function in Sigmaplot $12.5^{\circ}$. We conducted mixed Analyses of Variance (ANOVA) using IBM SPSS $25^{\circ}$ using the slope parameters as a dependent variable and, in a separate ANOVA, 
Citation: Sargisson RJ, Li F, Lobo D, Roche M (2019) Using an Acceptance and Commitment Therapy app to Reduce Anxiety for Students and Employees. Int J Psychol Behav Anal 5: 164. doi: https://doi.org/10.15344/2455-3867/2019/164

Page 3 of 6

scores on the pre- and post-questionnaire measures, to determine whether there was any improvement in dependent variable scores as a result of app use.

\section{Results}

\section{Pre-post questionnaire results}

Using the scores from each questionnaire as a dependent variable, we ran a series of mixed ANOVA with participant type (student vs. employee) as a between-subjects independent variable and administration time (pre- or post-app use) as a within-subject independent variable. Every test met the assumption of equality of error variances, according to individual Levene's tests. The results of each ANOVA were similar. Specifically, for every measure, there was a significant effect of administration time, with post-app scores improving in every instance from pre-app scores, but no main effect of participant type, and no interaction between participant type and administration time. This means that, in every case, scores improved to a similar degree for both students and employees following app use. The statistical results for each measure are given in Table 2 .

\section{Daily anxiety scores}

Daily scores on the DAS-A across phases for students consistently showed that, prior to app use, anxiety scores were increasing. During app use, anxiety scores, although variable, decreased gradually over time. Graphed results showed patterns for employees that were less clear. For two employees (E2 and E4), anxiety scores were increasing in baseline, while for three (E1, E5, and E7), they were

\begin{tabular}{|c|c|c|c|c|c|c|c|}
\hline & \multicolumn{2}{|c|}{ Mean } & \multicolumn{2}{|l|}{$95 \% \mathrm{CI}$} & \multirow[t]{2}{*}{$F$} & \multirow[t]{2}{*}{$p$} & \multirow[t]{2}{*}{$r$} \\
\hline & Pre & Post & Pre & Post & & & \\
\hline STAIS-Y1 & 50.4 & 38.5 & $45.5,55.3$ & $33.1,43.9$ & 9.7 & .006 & .60 \\
\hline STAIS-Y2 & 55.0 & 42.3 & $51.3,58.6$ & $37.6,47.1$ & 22.0 & $<.001$ & .75 \\
\hline HADS-A & 12.1 & 8.1 & $10.6,13.6$ & $6.6,9.6$ & 21.5 & $<.001$ & .75 \\
\hline HADS-D & 6.9 & 3.7 & $5.4,8.4$ & $2.6,4.7$ & 22.8 & $<.001$ & .76 \\
\hline PSS & 25.5 & 18.1 & $22.7,28.4$ & $14.6,21.6$ & 24.9 & $<.001$ & .77 \\
\hline PANAS-Positive & 27.0 & 32.3 & $24.3,29.6$ & $28.8,35.7$ & 9.8 & .006 & .60 \\
\hline PANAS-Negative & 26.9 & 17.4 & $23.5,30.3$ & $15.0,19.8$ & 25.4 & $<.001$ & .77 \\
\hline MAAS & 3.0 & 3.5 & $2.7,3.4$ & $3.0,4.0$ & 4.8 & .04 & .47 \\
\hline AAQ-II & 42.5 & 48.2 & $38.9,46.0$ & $44.2,52.3$ & 5.7 & .03 & .50 \\
\hline
\end{tabular}

Table 2: Statistical Results for Individual Mixed ANOVA Run with Each Questionnaire Pre- and Post-App Use. Note that in Every Case, the Degrees of Freedom for the Analysis were 1, 17.

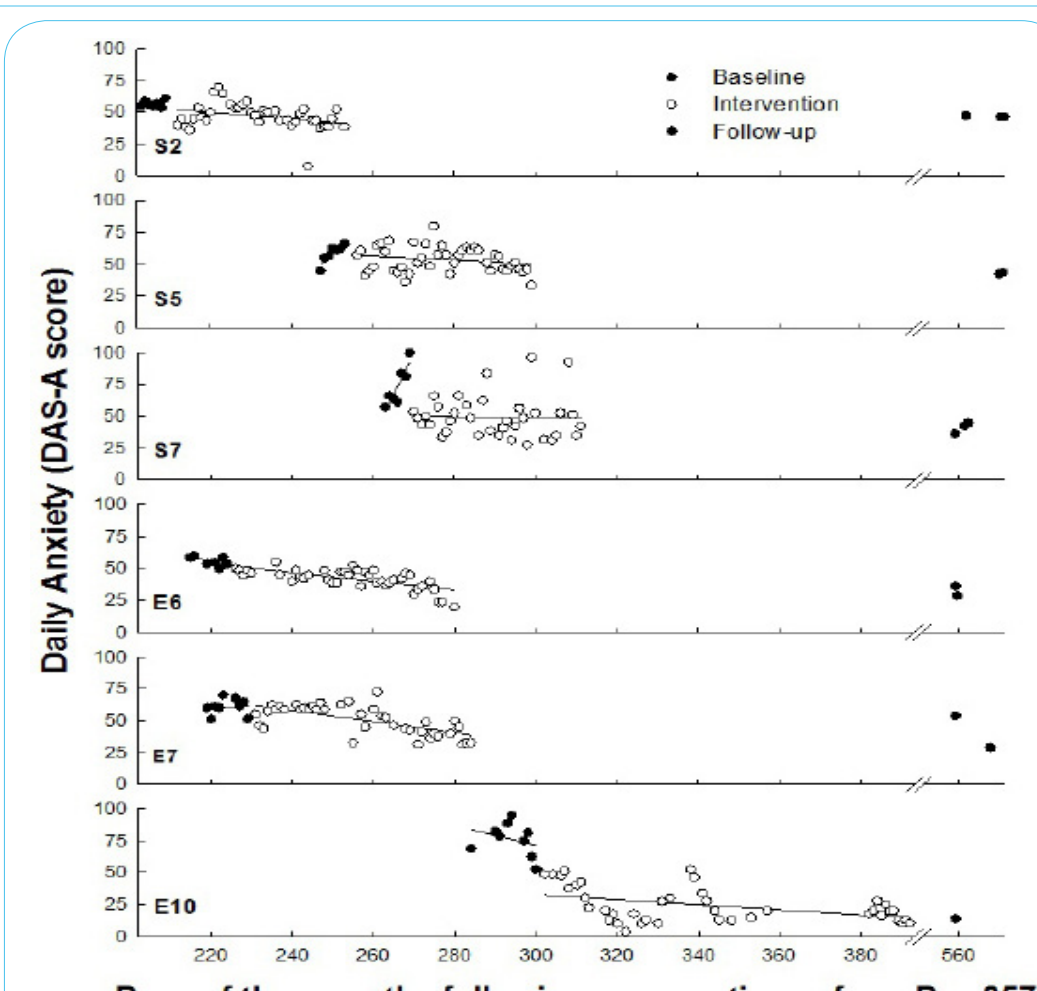

Days of the year; the following year continues from Day 357

Figure 1: Daily anxiety (DAS-A scores) for days of the year, where 1 January is Day 1, across baseline, intervention, and follow-up phases for Participants S2, S5, S7, E6, E7, and E10. In the second year, days begin from Day 357. 
neither trending upwards or downwards, and for the remaining five, scores were decreasing prior to app use. During app use, for some participants (E1, E2, E3, E6, E7, E8, and E10), daily anxiety scores decreased relatively steadily during app use. For others (E4, and E9), anxiety scores dropped almost immediately and then remained low and stable across the intervention phase. For E5, app use appeared to have little effect on DAS-A scores. Figure 1 shows the data for the six participants for whom we have follow-up data (S2, S5, S7, E6, E7, and E10). The data for these participants reflect patterns not dissimilar to those found for the remaining participants (not shown).

There was a significant effect of administration time (pre- and during-app use) on the slopes of straight lines fitted to daily data, $M_{\text {pre }}$ $=.82,95 \% \mathrm{CI}[.18,1.46], M_{\text {Post }}=-.29,95 \% \mathrm{CI}[-.40,-.17], F(1,17)=$ $14.32, p=.001, r=.67$. Mean slopes were positive prior to app use, showing that daily anxiety levels were increasing on average across baseline, and mean slopes of lines fitted to daily scores during app use were negative, showing that anxiety levels were decreasing. There was also a significant effect of participant type on slope values, $M_{\text {Employee }}=$ $-.29,95 \% \mathrm{CI}[-.76, .19], M_{\text {Student }}=.82,95 \% \mathrm{CI}[.32,1.32], F(1,17)=11.59$, $p=.003, r=.64$, indicating that student slope values were overall more positive than were employee slope values. The interaction between participant type and administration time was also significant, $F(1,17)$ $=16.84, p=.001, r=.71$. The interaction indicated that for employees, slopes changed little across administration time, but that slope values decreased for students from pre- to during-app use periods.

We calculated the mean of the last 3 days of DAS-A scores for baseline and intervention phases and used these means as dependent variable scores in a mixed ANOVA with phase (baseline vs. intervention) as a within-subject independent variable and participant type (student vs. employees) as a between-subject variable. There was a significant main effect of phase, $F(1,17)=68.79, p<.001, r=.90$, with baseline mean scores being significantly higher, $M=61.02$, 95\% CI[57.49, 64.56], than the mean scores recorded for the last 3 days of the intervention phase, $M=33.19,95 \% \mathrm{CI}[27.12,39.28]$. There was no main effect of participant type on mean daily DAS-A scores, $F(1$, $17)<1$, and no significant interaction between phase and participant type, $F(1,17)=1.21, p=.29, r=.26$. These results support those from the pre- and post-intervention measures showing that anxiety scores had decreased at the end of the intervention phase compared to those at the end of the baseline phase for both employees and students. Similar results were obtained when the mean follow-up DAS-A scores were entered into a mixed ANOVA with mean baseline DAS-A scores (results not given), showing that DAS-A scores remained low at follow-up, $M=36.42,95 \% \mathrm{CI}[26.78,46.06]$ compared to at the end of baseline (mean and CIs already given).

\section{Discussion}

We aimed to investigate the efficacy of a smartphone app for relieving anxiety among nine university students and 10 employees. For every measure used in the questionnaire battery, scores improved significantly following app use relative to baseline levels. There was no effect of participant type, and no interaction between participant type and the time that the tests were administered, showing that app use resulted in consistent positive outcomes for both university students and employees. The tests were designed to measure a variety of constructs, including state and trait anxiety and daily anxiety, stress, depression, positive and negative effect, and psychological flexibility. As the scores of all these tests improved, we conclude that use of the
ACTCompanion can result in improvement in a number of areas of people's lives. Similar improvements have been achieved through the use of other smartphones apps, such as an improvement in anxiety, depression, and psychological flexibility scores as a result of using the ACT Daily app [46].

Similar to the findings for the pre- and post-intervention measures, we found that daily scores of anxiety decreased significantly as a result of app use and remained low up to 9 months after the end of the study. Of the six participants who provided follow up data, only one reported that they were still using the app, suggesting that improvements engendered through app use were maintained in the absence of app use and potentially that the participants had learned to incorporate the app activities into their everyday lives.

Our finding that individual engagement with a widely available app had reliable and sustainable positive effects on people from two different populations is encouraging. As argued earlier, many people who require an psychological intervention do not receive one [2,3741], so effective interventions that have the potential to reach large numbers of people before their problems become overwhelming are extremely valuable.

One potential limitation of our study is related to the self-reported nature of the data, and, therefore, the possibility that participants reported improvements because of expectation effects. While we acknowledge this possibility, we doubt that the positive results found here were entirely attributable to such an effect. Evidence to support our position come from the follow-up data, as participants could not be reasonably expected to have remembered the way they were answering the DAS-A up to 9 months since they last completed it. Hence, we tentatively accept the improvements reported by the participants here as accurately reflecting their experience.

We used a single-subject, non-concurrent-baseline design across multiple participants which offers many advantages over other approaches [47]. A concurrent, multiple-baseline design requires that individuals begin the baseline condition at the same time, however, using a non-concurrent design made recruiting participants more convenient as each participant could start as they were recruited. This design was practical and flexible as not all individuals were available at the same time. In addition, each individual served as their own control, reducing variability and increasing validity. As argued by Singh, Starkey, and Sargisson [48], single-subject designs "hold great promise for evaluating the outcomes of mHealth behavioural interventions" (p. 8). Particularly, removing the requirement for large sample sizes enables evaluations which are much quicker to complete - an important consideration in the rapidly evolving field of mHealth [48].

\section{Acknowledgements}

We would like to thank the developers of the ACTCompanion ${ }^{\circledR}$ app, Anthony Berrick and Dr. Russ Harris, for supporting the study with free apps for our participants.

\section{Ethical Approval}

We gained ethical approval from the School of Psychology Research and Ethics Committee under delegated authority of the University of Waikato Human Research Ethics Committee. 
Citation: Sargisson RJ, Li F, Lobo D, Roche M (2019) Using an Acceptance and Commitment Therapy app to Reduce Anxiety for Students and Employees. Int J Psychol Behav Anal 5: 164. doi: https://doi.org/10.15344/2455-3867/2019/164

Page 5 of 6

\section{Funding}

The research was supported by the ACTCompanion ${ }^{\circledR}$ developers through the donation of free access to apps for our participants.

\section{Conflict of Interest}

The authors declare that they have no competing interests.

\section{References}

1. Hendriks SM, Spijker J, Licht CM, Hardeveld F, de Graaf R, et al. (2015) Long term work disability and absenteeism in anxiety and depressive disorders. Affect Disord 178: 121-130.

2. Eisenberg D, Gollust SE, Golberstein E, Hefner JL (2007) Prevalence and correlates of depression, anxiety, and suicidality among university students. Am J Orthopsychiatry 77: 534-542.

3. Hunt J, Eisenberg D (2010) Mental health problems and help-seeking behavior among college students. J Adolesc Health 46: 3-10.

4. Dewa CS, Lesage A, Goering P, Craveen M (2004) Nature and prevalence of mental illness in the workplace. Healthc Pap 5: 12-25.

5. Samaranayake CB, Arroll B, Fernando AT (2014) Sleep disorders, depression anxiety and satisfaction with life among young adults: A survey of university students in Auckland, New Zealand. N Z Med J 127: 13-22.

6. Goetzel RZ, Long SR, Ozminkowski RJ, Hawkins K, Wang S, et al. (2004) Health, absence disability, and presenteeism cost estimates of certain physical and mental health conditions affecting U. S. employers. J Occup Environ Med 46: 398-412.

7. Andrews B, Wilding JM (2004) The relation of depression and anxiety to lifestress and achievement in students. Br J Psychol 94: 509-521.

8. Hysenbegasi A, Hass SL, Rowland CR (2005) The impact of depression on the academic productivity of university students. J Mental Health Policy Econ 8: 145-151.

9. Lasalvia A, Bonetto C, Bertani M, Bissoli S, Cristofalo D, et al. (2009) Influence of perceived organizational factors on job burnout: Survey of community mental health staff. Br J Psychiatry 195: 537-554.

10. Paterson R, Adams J (2011) Professional burnout- a regulatory perspective. NZ Med J 124: 40-46.

11. Winer ES, Bryant J, Bartoszek G, Rojas E, Nadorff MR, et al. (2017) Mapping the relationship between anxiety, anhedonia, and depression. J Affect Disord 221: 289-296.

12. Kaufman J, Charney D (2000) Comorbidity of mood and anxiety disorders Depress Anxiety 12: 69-76.

13. Borkovec TD, Alcaine OM, Behar E (2004) Avoidance theory of worry and generalized anxiety disorder. In: Heimberg RG, Turk $C L$, and Mennin DS (eds) Generalized anxiety disorder: Advances in research and practice. New York: Guildford Press.

14. Mennin DS, Heimberg RG, Turk CL, Fresco DM (2005) Preliminary evidence for an emotion dysregulation model of generalized anxiety disorder. Behav Res Ther 43: 1281-1310.

15. Arch JJ, Craske MG (2008) Acceptance and commitment therapy and cognitive behavioral therapy for anxiety disorders: Different treatments, similar mechanisms? Clin Psychol: Sci Pract 15: 263-279.

16. Arch JJ, Eifert GH, Davies C, Plumb Vilardaga JC, Rose RD, et al. (2012) Randomized clinical trial of cognitive behavioral therapy (CBT) versus acceptance and commitment therapy (ACT) for mixed anxiety disorders. J Consult Clin Psychol 80: 750-765.

17. Hayes SC, Luoma JB, Bond FW, Masuda A, Lillis J, et al. (2006) Acceptance and commitment therapy: Model, processes and outcomes. Behav Res The 44: $1-25$

18. Hayes SC, Wilson KG, Gifford EV, Follette VM, Strosahl K, et al. (1996) Experiential avoidance and behavioral disorders: A functional dimensional approach to diagnosis and treatment. J Consult Clin Psychol 64: 1152-1168.

19. Abramowitz JS, Tolin DF, Street GP (2001) Paradoxical effects of thought suppression: A meta-analysis of controlled studies. Clin Psychol Rev 21: 683-703.
20. Fletcher L, Hayes S (2005) Relational frame theory, acceptance and commitment therapy, and a functional analytic definition of mindfulness. Rat-Emo Cognitive-Behav Ther 23: 315-336.

21. Danitz SB, Orsillo SM (2014) The mindful way through the semester: An investigation of the effectiveness of an acceptance-based behavioral therapy program on psychological wellness in first-year students. Behav Modif 38: 549-566.

22. Eifert GH, Forsyth JP, Arch J, Espejo E, Keller M, et al. (2009) Acceptance and Commitment Therapy for Anxiety Disorders: Three case studies exemplifying a unified treatment protocol. CognBehav Pract 16: 368-385.

23. Richardson T, Bramwell K (2018) Improvements in depression and mental health after Acceptance and Commitment Therapy are related to changes in defusion and values- based action. J Contemp Psychotherapy 1: 9-14.

24. Roemer L, Orsillo SM, Salters-Pedneault K (2008) Efficacy of an acceptancebased behavior therapy for generalized anxiety disorder: Evaluation in a randomized controlled trial. J Consult Clin Psychol 76: 1083-1089.

25. Biglan A, Layton GL, Jones LB, Hankins M, Rusby JC, et al. (2013) The value of workshops on psychological flexibility for early childhood special education staff. Top Early Childhood Special Educ 32: 196-210.

26. Bond FW and Bunce D (2000) Mediators of change in emotion-focused and problem-focused worksite stress management interventions. J Occup Health Psychol 5: 156-163.

27. Brinkborg H, Michanek J, Hesser H, Berglund G (2011) Acceptance and commitment therapy for the treatment of stress among social workers: A randomized controlled trial. Behav Res Ther 49: 389-398.

28. Moran D (2015) Acceptance and Commitment training in the workplace. Curr Opin Psychol 2: 26-31.

29. Wersebe $H$, Lieb $R$, Meyer AH, Hofer P, Gloster AT, et al. (2018) The link between stress, well-being, and psychological flexibility during an Acceptance and Commitment Therapy self-help intervention. Int J Clin Health Psychol 18: 60-68.

30. Ong JC, Ulmer CS, Manber R (2012) Improving sleep with mindfulness and acceptance: A metacognitive model of insomnia. Behav Res Ther 50: 651660.

31. Svanberg G, Munck I, Levander M (2017) Acceptance and commitment therapy for clients institutionalized for severe substance-use disorder: pilot study. Subst Abuse Rehab 8: 45-51

32. Dalrymple KL, Herbert JD (2007) Acceptance and commitment therapy for generalized social anxiety disorder: A pilot study. Behav Modification 31 543-568.

33. Orsillo SM, Batten SV (2005) Acceptance and Commitment Therapy in the Treatment of Posttraumatic Stress Disorder. Behavior Modification 29: 95 129

34. McEvoy PM, Nathan P, Norton PJ (2009) Efficacy of transdiagnostic treatments: A review of published outcome studies and future research directions. J Cogn Psychother 23: 20-33.

35. Hayes SC, Pistorello J, Levin ME (2012) Acceptance and commitment therapy as a unified model of behavior change. CounselPsychol 40: 976-1002.

36. Jaworska N, De Somma E, Fonseka B, Heck E, MacQueen GM, et al. (2016) Mental health services for students at postsecondary institutions: A national survey. Can J Psychiatry 61: 766-775.

37. Gulliver A, Griffiths KM, Christensen H (2010) Perceived barriers and facilitators to mental health help-seeking in young people: A systematic review. BMC Psychiatry 10: 113.

38. McKinney KG (2009) Initial evaluation of active minds: a student organization dedicated to reducing the stigma of mental illness. J College Student Psychotherapy 23: 281-301.

39. Vogel DL, Wade NG, Hackler AH (2007) Perceived public stigma and the willingness to seek counseling: The mediating roles of self-stigma and attitudes toward counseling. J Counsel Psychol 54: 40-50.

40. Zivin $\mathrm{K}$, Eisenberg D, Gollust $\mathrm{SE}$, et al. Persistence of mental health problems and needs in a college student population. J Affect Disord 117: 180-185.

41. Andrews G, Issakidis C, Carter G (2001) Shortfall in mental health service utilisation. Br J Psychiatry 179: 417-425.

42. Sandholzer M, Deutsch T, Frese T, Winter A, et al. (2015) Predictors of students' self-reported adoption of a smartphone application for medical education in general practice. BMC Med Ed 15: 91. 
Citation: Sargisson RJ, Li F, Lobo D, Roche M (2019) Using an Acceptance and Commitment Therapy app to Reduce Anxiety for Students and Employees. Int J Psychol Behav Anal 5: 164. doi: https://doi.org/10.15344/2455-3867/2019/164

Page 6 of 6

43. Aboujaoude E, Salame W, Naim L (2015) Telemental health: A status update. World Psychiatry 14: 223-230.

44. Ly KH, Asplund K, Andersson G (2014) Stress management for middle managers via an acceptance and commitment-based smartphone application: A randomized controlled trial. Internet Interventions 1: 95-101.

45. Firth J, Torous J, Nicholas J, Carney R, Rosenbaum S, et al. (2017) Can smartphone mental health interventions reduce symptoms of anxiety? A meta-analysis of randomized controlled trials. J Affect Disord 218: 15-22.

46. Levin ME, Haeger J, Pierce B, Cruz RA (2017) Evaluating an Adjunctive Mobile App to Enhance Psychological Flexibility in Acceptance and Commitment Therapy. Behav Modification 41: 846-867.

47. Butler R, Sargisson RJ, Elliffe D (2011) The efficacy of systematic desensitization for treating the separation-related problem behaviour of domestic dogs. Appl Anim Behav Sci 129: 136-145

48. Singh S, Starkey N, Sargisson R (2017) Using SmartQuit ${ }^{\circledR}$, an Acceptance and Commitment Therapy Smartphone application, to reduce smoking intake. Digital Health 3: 1-9. 